\title{
Characterization of ancient Indian iron and entrapped slag inclusions using electron, photon and nuclear microprobes
}

\author{
P DILLMANN ${ }^{\dagger}$ and R BALASUBRAMANIAM* \\ Department of Materials and Metallurgical Engineering, Indian Institute of Technology, Kanpur 208 016, India \\ ${ }^{\dagger}$ Laboratoire Pierre Süe CEA/CNRS, CE Saclay 91191, Gif sur Yvette Cedex, France
}

MS received 8 February 2001; revised 29 March 2001

\begin{abstract}
Compositional and structural information were obtained from an ancient 1600-year old Indian iron using microprobe techniques (EDS, $\mu$ XRD and $\mu$ PIXE). Several different local locations in the iron matrix and in the entrapped slag inclusions were analyzed. The $P$ content of the metallic iron matrix was very heterogeneous. Lower $P$ contents were observed in the regions near slag inclusions. This was correlated to the dephosphorization capacity of the slag. The crystallized phases identified in the slag inclusions were wüstite and fayalite. The compositions of the slag inclusions were relatively homogeneous.
\end{abstract}

Keywords. Ancient iron; slag inclusions; characterization; electron, photon and nuclear microprobe techniques.

\section{Introduction}

The corrosion resistance of ancient Indian iron has been debated for several decades (Ghosh 1963; Lahiri et al 1963; Prakash and Tripathi 1986; Prakash 1991; Balasubramaniam 1995; Anantharaman 1997). A shining example of the excellent corrosion resistance of ancient Indian iron (dating to period before the tenth century AD) is the Delhi iron pillar, a 1600-year old structure that has withstood significant corrosion damage. A detailed characterization of the oldest Delhi iron pillar (DIP) rust (Balasubramaniam and Ramesh Kumar 2000) has established that DIP obtains its excellent corrosion resistance due to the formation of a protective crystalline iron hydrogen phosphate hydrate at the interface between the metal and the atmospheric rust (Balasubramaniam 2000). One of the reasons for the formation of this phosphate is the availability of a significant amount of $\mathrm{P}$ in the underlying metal. Based on several reported analyses, the average $\mathrm{P}$ content in the Delhi pillar iron has been reported to be $0.24 \%$ (Balasubramaniam 2000). Moreover, available compositions from ancient Indian iron objects indicate relatively high P contents (Ghosh 1963; Lahiri et al 1963; Prakash and Tripathi 1986; Prakash 1991). The high $P$ content could originate either from the ore or from the charcoal ash. The former appears likely as Indian iron ores are relatively rich in $\mathrm{P}_{2} \mathrm{O}_{5}$. However, the $\mathrm{P}$ content of the metallic matrix is determined by the slag composition in the shaft furnace. The use of limestone in the charge of ancient Indian shaft furnaces is not attested. Thus, the

*Author for correspondence eventual presence of $\mathrm{CaO}$ in the charge must be linked to the ore composition. The efficient dephosphorization capacity of $\mathrm{CaO}$ is well recognized (Turkdogan 1996). Therefore, in the absence of $\mathrm{CaO}$ in the slag, a greater amount of $\mathrm{P}$ can be left behind in the metal. In order to gain further insights into the operating conditions of ancient furnaces, it becomes important to obtain accurate chemical compositions and structural analyses (both from the metal and the entrapped slag inclusions) from ancient Indian iron.

As the ancient iron-making process did not utilize smelting of the metal, ancient irons possess very heterogeneous compositions (Ghosh 1963; Lahiri et al 1963; Prakash 1991). The minor element (C, P, Si, etc) content can vary depending on the location in the sample (Ghosh 1963). Moreover, ancient irons invariably contain entrapped slag inclusions. These entrapped slag inclusions result from the process by which iron was made (Lahiri et al 1963; Prakash and Tripathi 1986; Prakash 1991). In order to understand all the local compositions and structures, it is necessary to use characterization techniques that are capable of sampling very localized locations. The present paper outlines the application of some microdiffraction techniques $(\mu \mathrm{XRD}$ performed with a photonic microprobe and $\mu$ PIXE performed with a nuclear microprobe) to determine localized metal (and slag) compositions and structures in an ancient Indian iron. Indeed, the strong heterogeneity of these kinds of samples needs the use of microbeams. Moreover, to understand the complex mechanisms linked to the production of ancient iron and to understand the influence of the structure and composition on properties (like, say, corrosion behaviour), it is necessary to obtain very fine local information about 
structure and composition. Therefore, a combination of photonic, electronic and nuclear microprobe techniques (like $\mu \mathrm{XRD}$, EDS and $\mu \mathrm{PIXE}$ ) provide valuable insights.

The iron (from an iron clamp) utilized in the present analysis was obtained from an ancient Gupta temple (now in ruins) at a site called Eran in Madhya Pradesh in Central India. Inscriptions in the temple site indicate that the temple was constructed in the later half of the fifth century AD (Tripathi 1992). The corrosion behaviour of this iron has been investigated (Puri et al 1997) and the atmospheric corrosion products characterized (Ramesh Kumar and Balasubramaniam 1998). As these two earlier studies did not consider microscopic compositional and structural variations of the metal and the slag inclusions, this aspect will be highlighted in the present communication.

\section{Experimental}

\subsection{Sample preparation}

Two different sample preparation methods were utilized, depending on the analysis technique. In the first method, a polished section of the material (ancient Indian iron with entrapped slag inclusions) was prepared after mounting the specimen in epoxy resin and polished with $\mathrm{SiC}$ paper (grades 180 through 2500) and diamond paste (3 and $1 \mu \mathrm{m})$. This mounted specimen was observed in Cambridge Stereoscan 120 scanning electron microscope (SEM). The same sample was also utilized for analysis with the nuclear microprobe of the Pierre Süe Laboratory for PIXE analyses. However, the X-ray microdiffraction analysis, performed at LURE, requires to be conducted in the transmission mode. Therefore, after mounting the specimen in the resin, a thin film of $20 \mu \mathrm{m}$ thickness was prepared. In order to accomplish this, first, a slide of the mounted sample was cut with a diamond cutting wheel. This slide was later mechanically trimmed and polished with 1200 grade $\mathrm{SiC}$ paper. One of the faces of the thin film was fine polished with $3 \mu \mathrm{m}$ diamond paste so that it could be observed with an Olympus optical microscope (OM). The thin film was deposited on a $30 \mu \mathrm{m}$ kapton scotch tape and the final sample was carbon coated by sputtering. In this way, the thin film could be observed in the OM and SEM. Specific localized regions of interest were then investigated by X-ray microdiffraction.

\subsection{Techniques}

The metallographically polished section and the thin film were both examined by optical microscopy and SEM. The major elements in the inclusion and in the oxide scales were detected by energy dispersive spectrometry (EDS), coupled to the SEM operating at $20 \mathrm{keV}$, using a $\mathrm{Si}(\mathrm{Li})$ detector with a thin beryllium window.

To detect the minor and trace elements in the material, the micro particles induced X-ray emission ( $\mu$ PIXE) method was utilized. A detailed description of the PIXE method is described elsewhere (Johansson and Campbell 1988). The PIXE method is a convenient method to chemically analyze the sample because it quantifies relatively low amounts of elements ( $Z$ higher than 12 ) in the metallic matrix and allows simultaneous multi-elemental analyses. This aspect is important specially when studying archaeological iron samples because they usually contain various concentrations of minor elements (phosphorus and silicon, for example). The $1.5 \mathrm{MeV}$ proton beam of the Pierre Süe Laboratory (at CEA Saclay, France) nuclear microprobe was used. This energy was selected to favour the X-ray emission corresponding to the lighter elements. The beam current was about $150 \mathrm{pA}$ for a $2 \times 2 \mu \mathrm{m}^{2}$ beam spot size. The distance between the sample and the X-ray $\mathrm{Si}(\mathrm{Li})$ detector (positioned at $45^{\circ}$ from the incident beam) was $6 \mathrm{~cm}$. A $15 \mu \mathrm{m}$ Mylar filter was used to reduce Fe pill-up peaks. The data collected were analyzed with the GUPIX 99 program. The relative error obtained on the quantitative results is about $5 \%$. The profile data were computerized with the RISMIN program. The detailed experimental procedure is provided elsewhere (Neff and Dillmann 2001). A reference sample of low-alloyed steel containing 450 ppm phosphorus was utilized.

The X-ray microdiffraction $(\mu \mathrm{XRD})$ experiments were conducted on the D15 beamline at Laboratoire pour l'Utilisation du Rayonnement Electromagnetique (LURE) at Orsay, France. The white X-ray beam delivered by the DCI ring was focused and monochromatized by a carbon/ tungsten(C/W) Bragg Fresnel Multilayer Lens (BFML) (Chevallier et al 1996). The BFML is a wide band pass monochromator resulting in broadening of the diffraction peaks. Photons centred around $14 \mathrm{keV}(\lambda=0 \cdot 8857 \AA)$ were selected and focused down to a $10 \times 10 \mu^{2}$ beam. The diffraction patterns were collected with an image plate downstream the sample. A detailed description of the experimental set-up is provided in Dillmann et al (1997, 2000). 1-D diffraction patterns were obtained by circularly integrating diffraction rings using the FIT2D software developed at the European Synchrotron Radiation Facility (ESRF) (Hammersley et al 1996). The reference sample used was silicon powder. The spectra were compared with the JCPDF database using the Diffrac ${ }^{+}$ program.

Simultaneous with the X-ray microdiffraction measurements, the fluorescence signal emitted by the sample was detected at $90^{\circ}$ from the direct beam. Due to the absorption of the low energy photons by air present between the sample and the detector, only elements heavier than potassium could be detected. The micro X-ray fluorescence under focalized synchrotron radiation $(\mu \mathrm{SXRF})$ data were analyzed with the WAPI software (Wang 1995). 


\section{Results and discussion}

Two distinctly different localized zones of the ancient Indian iron sample were analyzed: the iron matrix and the entrapped slag inclusions (particularly, the ones that were surrounded by an oxide scale).

\subsection{Iron matrix}

The composition of ancient iron is heterogeneous in nature because of the nature of the ancient iron making processes (Prakash and Tripathi 1986; Prakash 1991). Therefore, it was important to compositionally analyze the

Table 1. Phosphorus content in the $\mathrm{Fe}$ matrix (wt. ppm). Points 7 and 9 were collected from near metaloxide interfaces at two different locations.

\begin{tabular}{lc}
\hline Point & P (wt. ppm) \\
\hline 1 & 1371 \\
2 & 1462 \\
3 & 1151 \\
4 & 2179 \\
5 & 1531 \\
6 & 570 \\
7 & 2300 \\
8 & 1309 \\
9 & 750 \\
\hline
\end{tabular}

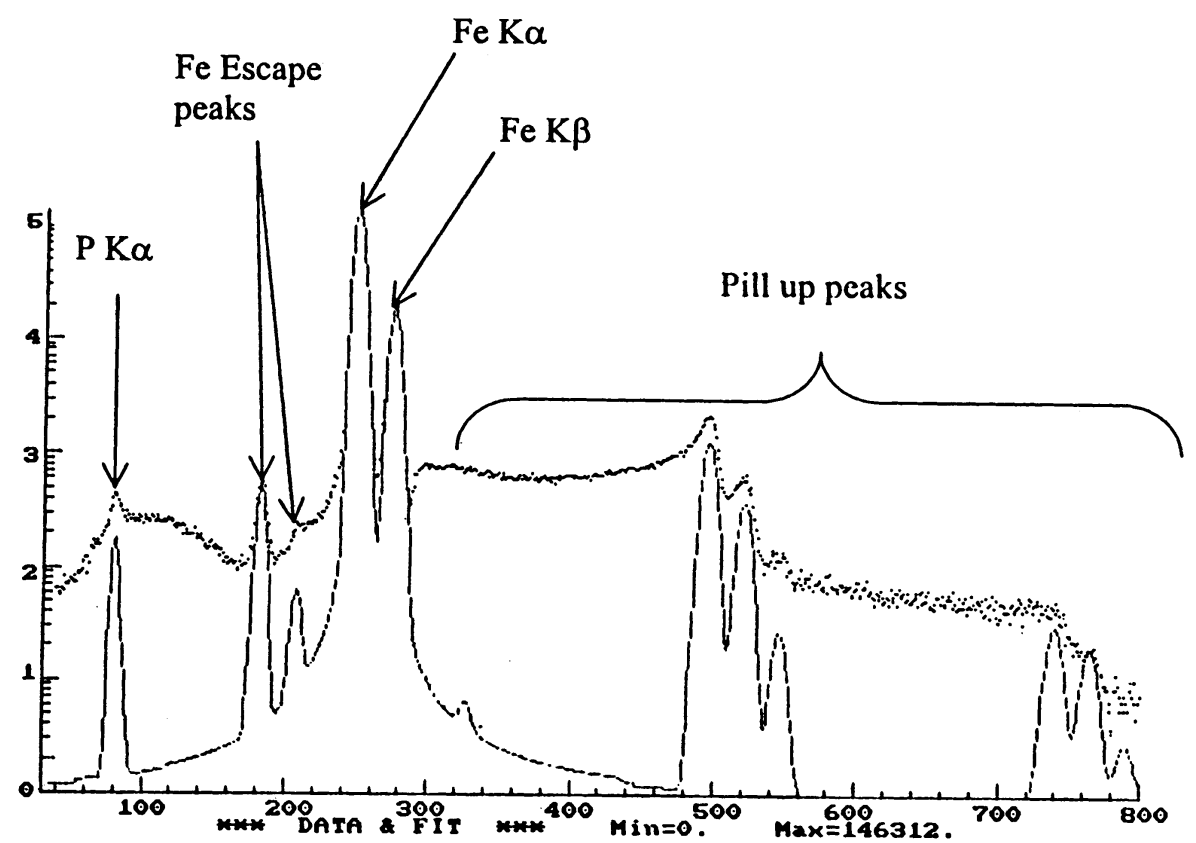

Figure 1. A typical $\mu \mathrm{PIXE}$ spectrum obtained from the iron matrix in ancient Indian iron. Notice the distinct presence of $\mathrm{P}$ in the metal. The composition of $\mathrm{P}$ was obtained from the spectrum. compared with modern steels). iron matrix at different locations in order to examine the variation of the minor elements' compositions. In the present sample, the phosphorus content was examined at different points of the matrix using the $\mu$ PIXE method. A typical $\mu$ PIXE spectrum is provided in figure 1 . Several different points were chosen in the iron matrix and the $\mathrm{P}$ contents determined at these locations are provided in table 1. Some details about the $\mathrm{P}$ contents determined should be noted. First, the data shows a wide variation in the $\mathrm{P}$ content thereby indicating the heterogeneous nature of the iron matrix. The global $\mathrm{P}$ content of the same material (including the $\mathrm{P}$ in metal as well as in the slag) was determined by wet chemical analysis and this was found to be $0.25 \%$ (Ramesh Kumar and Balasubramaniam 1998). However, the $P$ content in the metal can fluctuate from 570 to $2300 \mathrm{ppm}$ depending on the location. Points 7 and 9 were both collected near the metal/oxide interface but at different locations of the sample. The enhancement of $P$ near the metal surface observed by an electron probe microanalyzer (EPMA) (Ramesh Kumar and Balasubramaniam 1998) is partially verified, although the EPMA study did not report the regions of lower $\mathrm{P}$ content. Secondly, the relatively higher amount of $\mathrm{P}$ content in the Gupta period ancient Indian iron has to be noted (when

A phosphorus concentration profile was obtained with the $\mu$ PIXE method in the metallic matrix near a slag inclusion (see figure 2). As observed in other phosphoric ancient irons (Neff and Dillmann 2001), the profile revealed decreasing $\mathrm{P}$ content near the slag inclusion (for distances less than $10 \mu \mathrm{m}$ ). This effect must result due to the dephosphorizing power of the slag. At locations 
further away from the inclusions (about 40-50 $\mu \mathrm{m}$ ), the variation in the phosphorus content were similar to that typically observed in the metallic matrix.

\subsection{Entrapped inclusion}

The global composition of several inclusions was determined by EDS coupled to SEM (see table 2). These results indicate the relative homogeneity of compositions of the inclusions. Quantitative $\mu$ PIXE analyses were not performed in the slag inclusion because the interpretation of $\mu$ PIXE spectra is very complex in multiphase samples.

The compositions determined by the EDS alone does not provide any information about the nature (i.e. structure, phase composition, etc) of the entrapped inclusions. It is in this regard that the $\mu \mathrm{XRD}$ analyses are very useful in determining local structure of the phases that constitute

Table 2. Typical composition of inclusions (at \%) that were analyzed by EDS.

\begin{tabular}{llrl}
\hline Inclusion & $\mathrm{Si}$ & $\mathrm{P}$ & $\mathrm{Fe}$ \\
\hline 1 & 30 & 6 & 64 \\
2 & 26 & 8 & 65 \\
3 & 25 & 11 & 64 \\
4 & 24 & 7 & 68 \\
\hline
\end{tabular}

the inclusions. A typical example is presented below to provide the insights given by the $\mu \mathrm{XRD}$ analysis technique in understanding local nature of an entrapped inclusion in the ancient Indian iron.

The SEM metallograph of an entrapped slag inclusion that was sampled by $\mu$ XRD is presented in figure 2 . The $\mathrm{OM}$ and EDS observations revealed that the inclusion was made of wüstite dendrites entrapped in a polyphased matrix. One part of this slag appeared to be made of glassy phases but some other areas were crystallized. The $\mu \mathrm{XRD}$ analyses reveal that these crystallized areas were made of fayalite $\mathrm{Fe}_{2} \mathrm{SiO}_{4}$ (figure 3). The presence of wüstite dendrites in glassy and fayalitic slags in ancient Indian iron is usually the case as the main constituents of ancient Indian iron-making slags were $\mathrm{SiO}_{2}$ and $\mathrm{FeO}$. No other crystallized phase could be detected in the inclusions. The fact that the diffraction peaks of wüstite do not appear on the spectrum can be easily explained by the fact that the dendrite is monophased. Thus the FeO crystal is not well oriented to diffract under the monochromatic beam. The wüstite dendrites are monocrystals. If these are sampled with a monochromatic X-ray beam, there is no chance to be in the right position to obtain diffraction peaks (Bragg position). Diffraction is obtained from polycrystals. EDS analyses reveal that in addition to $\mathrm{Fe}, \mathrm{Si}$ and $\mathrm{O}$, the inclusions also contained $\mathrm{P}$. The absence of phosphates diffraction peaks on the $\mu$ XRD spectrum revealed that the phosphates contained in the inclusions were glassy in nature.

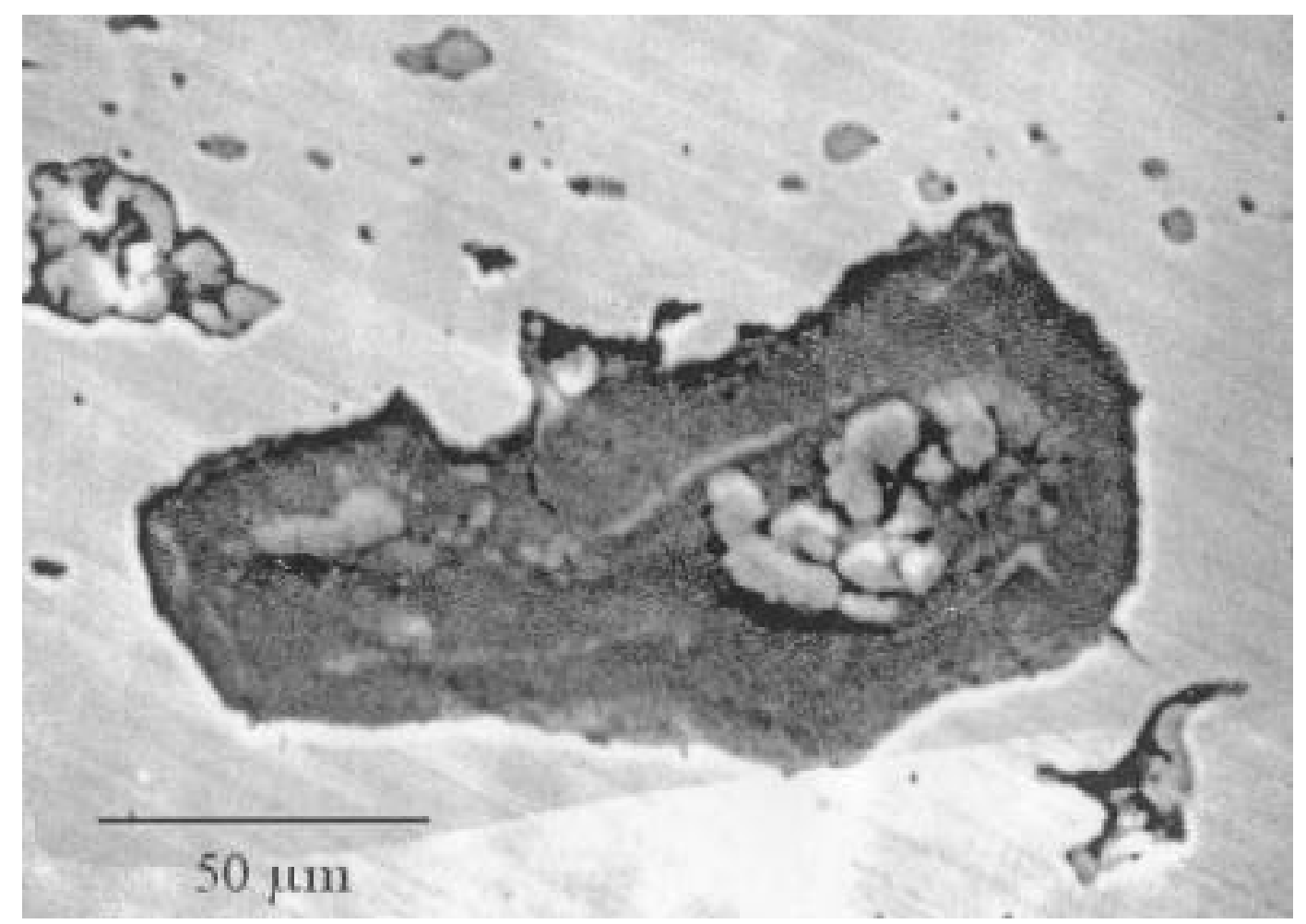

Figure 2. SEM micrograph of an entrapped slag inclusion in the iron matrix. 
Several inclusions, like the one presented in figure 2, were surrounded by an oxide phase near the metal/oxide interface. Microdiffraction experiments were also conducted to examine the oxide surrounding the inclusion of figure 3 . The spectrum obtained is shown in figure 4 . This oxide is made of goethite $(\alpha-\mathrm{FeOOH})$. The iron peaks that can be observed on the spectrum are due to the iron matrix. The surrounding oxide appears most likely to be a corrosion product, as the material had been handled in the atmosphere for some time. This could be either from the slag (wüstite being later converted to goethite) or metal (oxidation of the metallic matrix in the zone surrounding

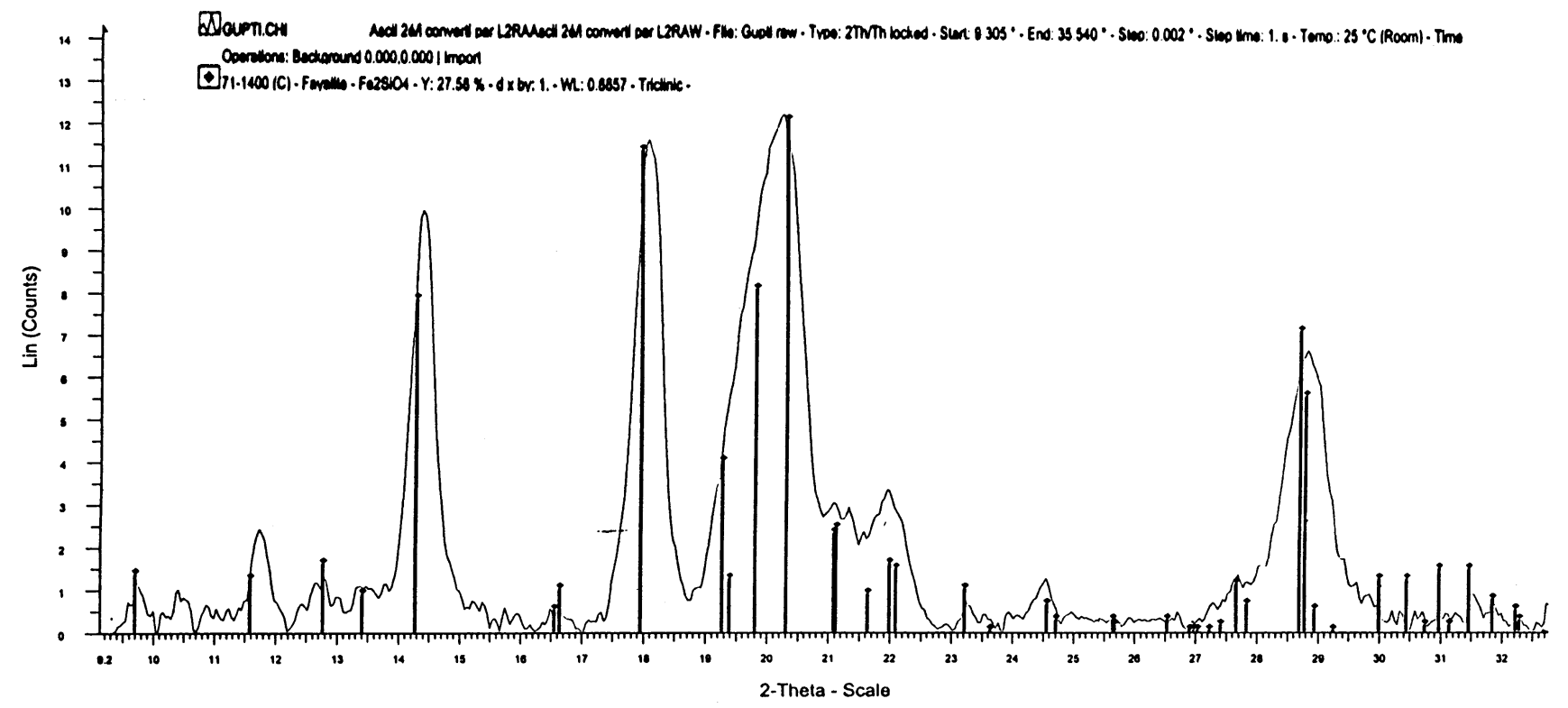

Figure 3. $\mu \mathrm{XRD}$ pattern from the interior of the inclusion presented in figure 2, identifying the presence of fayalite.

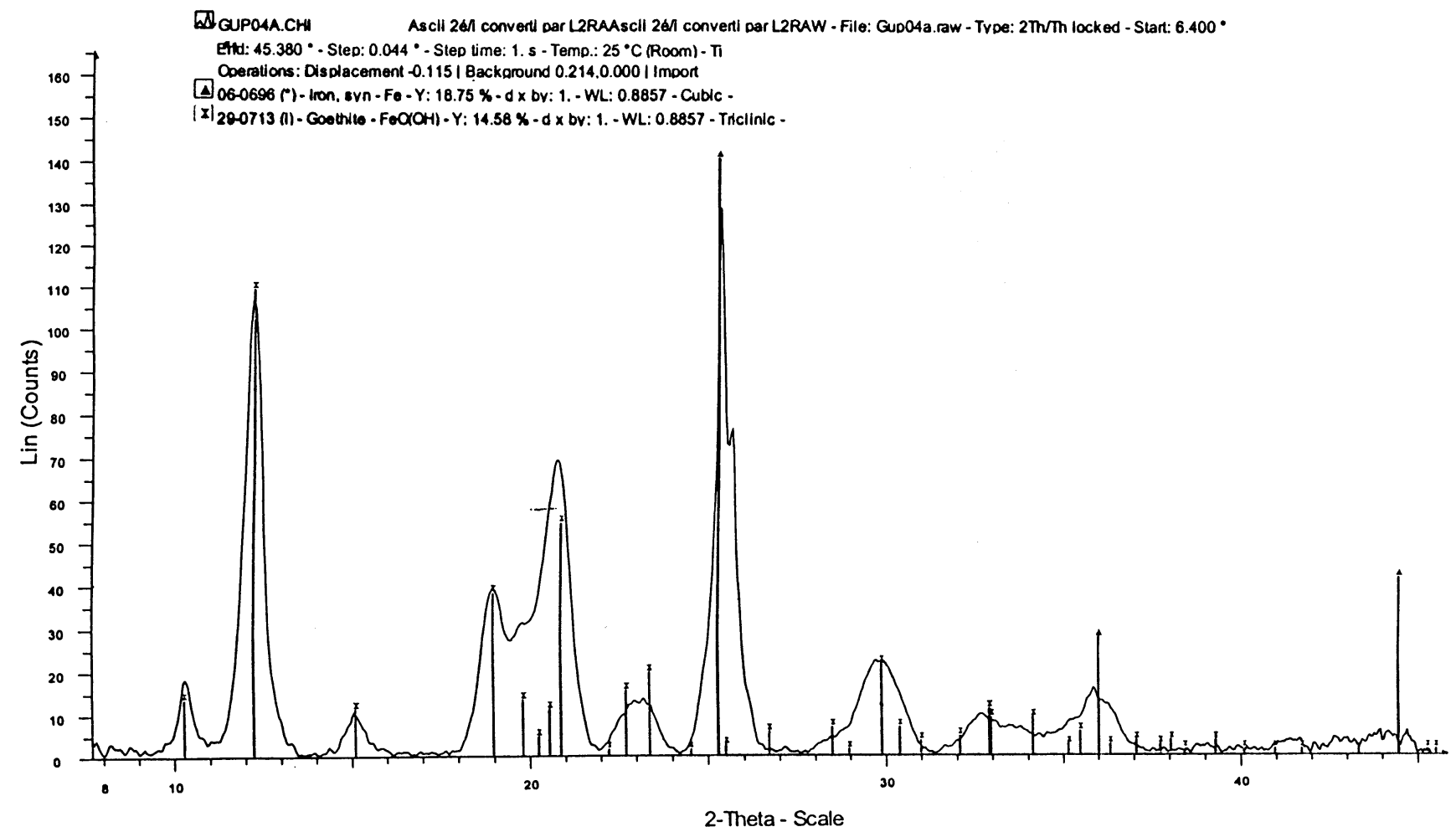

Figure 4. Microdiffraction spectrum from the region in the inclusion of figure 2 obtained near the metal-inclusion interface. The identified phase is goethite $(\alpha-\mathrm{FeOOH})$. The iron peaks that can be observed on the spectrum are due to the iron matrix. 
the inclusion). The latter appears reasonable because wüstite is entrapped in a (relatively stable) fayalite matrix.

\section{Conclusions}

Local compositions from the iron matrix and entrapped slag inclusions in an ancient 1500-year old Indian iron were determined using microprobe techniques (EDS, $\mu \mathrm{XRD}$ and $\mu \mathrm{PIXE})$. The $\mathrm{P}$ content of the metallic matrix was very heterogeneous (varying between $570 \mathrm{ppm}$ and $2300 \mathrm{ppm}$ ). These observations are in agreement with earlier studies on ancient phosphorus-containing irons. The crystallized phases identified in the slag inclusions were wüstite and fayalite. The $\mathrm{P}$ content in the iron matrix was lower near the slag inclusion due to the dephosphorization capacity of the slag. The advantage of utilizing different microdiffraction techniques to understand local compositions in ancient Indian iron has been highlighted.

\section{Acknowledgement}

The cooperation of the Archaeological Survey of India is gratefully acknowledged.

\section{References}

Anantharaman T R 1997 The rustless wonder - a study of the Delhi iron pillar (New Delhi: Vigyan Prasar)

Balasubramaniam R 1995 NML Tech. J. 37123
Balasubramaniam R 2000 Corr. Sci. 422103

Balasubramaniam R and Ramesh Kumar A V 2000 Corr. Sci. 422085

Chevallier P, Dhez P, Legrand F, Erko A, Agafonov Y, Panchenko L A and Yakshin A 1996 J. Trace and Microprobe Techniques $\mathbf{1 4} 517$

Dillmann P, Populus P, Chevallier P, Fluzin P, Béranger G and Firsov A 1997 J. Trace and Microprobe Techniques 13251

Dillmann P, Regad B and Moulin G 2000 J. Mater. Sci. Lett. 19 907

Ghosh M K 1963 NML Tech. J. 531

Hammersley A P, Svensson S, Hanfland M, Fitch A N and Hausermann D 1996 High Press. Res. 14235

Johansson S A E and Campbell J L 1988 PIXE, a novel technique for elemental analysis (New York: John Wiley and Sons)

Lahiri A K, Banerjee T and Nijhawan B R 1963 NML Tech. J. 5 46

Neff D and Dillmann P 2001 Nuclear Instrum. \& Meth. B (accepted)

Prakash B 1991 Ind. J. Hist. Sci. 261351

Prakash B and Tripathi V 1986 Met. \& Mater. 2568

Puri V, Balasubramaniam R and Ramesh Kumar A V 1997 Bull. Metals Museum 281

Ramesh Kumar A V and Balasubramaniam R 1998 Corr. Sci. 401169

Tripathi R S 1992 History of ancient India (New Delhi: Motilal Banarsidass Publishers) p. 252

Turkdogan E T 1996 Fundamentals of steel making (London: Institute of Materials) p. 186

Wang J X 1995 Utilisation du rayonnement synchrotron pour la détermination d'éléments traces par fluorescence, $\mathrm{Ph} \mathrm{D}$ Thesis, Orsay University, Paris 